\title{
Seven Decades of Primary Healthcare during Various Development Plans in Iran: A Historical Review
}

\author{
Leila Doshmangir, MSc, PhD ${ }^{1,2,3}$; Esmaeil Moshiri, MD, PhD ${ }^{4 *}$ Farshad Farzadfar, MD, $\mathrm{PhD}^{5,6}$ \\ ${ }^{1}$ Social Determinants of Health Research Center, Health Management and Safety Promotion Research Institute, Tabriz University of Medical \\ Sciences, Tabriz, Iran \\ ${ }^{2}$ Tabriz Health Services Management Research Center, Iranian Center of Excellence in Health Management, Tabriz University of Medical \\ Sciences, Tabriz, Iran \\ ${ }^{3}$ Department of Health Policy and Management, School of Management and Medical Informatics, Tabriz University of Medical Sciences, \\ Tabriz, Iran \\ ${ }^{4}$ Social Determinants of Health Research Center, Semnan University of Medical Sciences, Semnan, Iran \\ ${ }^{5}$ Non-Communicable Diseases Research Center, Endocrinology and Metabolism Population Sciences Institute, Tehran University of Medical \\ Sciences, Tehran, Iran, \\ ${ }^{6}$ Endocrinology and Metabolism Research Center, Endocrinology and Metabolism Clinical Sciences Institute, Tehran University of Medical \\ Sciences, Tehran, Iran
}

\begin{abstract}
Objective: To explore historically primary healthcare (PHC) development in Iran in the light of development plans before and after the Islamic Revolution. The results of this study can be used to outline the future of PHC in the Iranian health system.

Methods: We conducted a retrospective analysis of the PHC development in the Iranian health system using data from relevant published and unpublished policy documents. The literature was retrieved and reviewed on the basis of predetermined inclusion criteria with no language or date restriction. The data were integrated and analyzed using content analysis.

Results: During various upstream development plans, the attitude of the policy makers to PHC has been very different, resulting in fundamental differences in addressing such an important issue and the consequent outcomes. In the aftermath of Iran's revolution, due to more understanding of PHC services importance and the principal slogans of the revolution to pay attention to villagers and vulnerable people, health policymakers paid more attention to PHC, which was not evident in previous periods.

Conclusions: Despite considerable achievements in PHC, the history of PHC in Iran indicates frequent changes in planning and health provision structure. This suggests that the challenges facing the health sector today, the evolving needs and demands of the people, and population changes necessitate reinforcement and reform in the structure of the current PHC network as the main mission of Iran's Ministry of Health.

Keywords: Health reform, Iran, Policy plan, Primary healthcare, Public health

Cite this article as: Doshmangir L, Moshiri E, Farzadfar F. Seven decades of primary healthcare during various development plans in Iran: a historical review. Arch Iran Med. 2020;23(5):338-352. doi: 10.34172/aim.2020.24.
\end{abstract}

Received: September 25, 2019, Accepted: January 26, 2020, ePublished: May 1, 2020

\section{Introduction}

Several decades before the adoption of the Alma-Ata Declaration in 1979, extension of primary healthcare (PHC) to some villages and cities and the need to employ community health workers to provide PHC were recognized as a priority, especially in low-income countries. ${ }^{1}$ Countries such as Ethiopia, Nepal, Bangladesh, Peru, Guatemala, and Iran have experienced the use of community health workers in health care programs..$^{2-4}$ In some countries, this idea led to large-scale national programs, the most prominent example of which is "barefoot doctors" in China.,

Every individual is entitled to health, and public health policies are the direct result of this principle. Both from a humanist perspective and due to the inherent requirements of a universal public health system, maintaining PHC and preventive activities have priority over curative activities.

In Iran, during different periods of policy making, based on the attitude and intellectual trends of various policy makers which appear in the upstream country plans and their policy decisions, the interventions and policy initiatives towards PHC have been different. Thus, this paper aims to historically review the PHC development during the different periods of designing and implementing Iran's development plans.

\section{Materials and Methods}

We conducted a retrospective analysis of the PHC development in Iran. We reviewed the literature to outline the future of PHC in the Iranian health system. We searched six international databases (PubMed, ISI Web of Science, Scopus, Google Scholar, ProQuest, and 
Ovid) and five national databases (Scientific Information Database (SID), IranMedex, MagIran, IranDoc and MedLib) using search terms including primary health care, primary care, health system, health network, development plan, national policy, and Iran. The search terms were combined using the Boolean operators 'OR', and 'AND' to combine concepts to develop the final search strategy, We comprehensively screened and reviewed the literature to retrieve published articles as well as published and unpublished policy documents with no language or date restrictions. We also searched the gray literature from the website of the Ministry of Health and Medical Education (MoHME), medical sciences universities, Government of Iran, Islamic Parliament of Iran, and health insurance organizations. The review took place between October and November 2018. We included the articles and policy documents if they met the following criteria: 1) study was on public health and PHC, 2) Iranian setting, and 3) development plans to report the results. We precisely read, conceptualized and construed the documents to detect segments of the texts that contained the information relevant to the PHC and other inclusion criteria. After doing content analysis, the obtained data were classified into two periods (before and after the Islamic Revolution) based on the nature of the interventions at the primary care level.

\section{Patient and Public Involvement}

No patients or members of the public were involved in this study.

\section{Results}

Public Health Development in Iran

During the last decades, Iranian health authorities have tried to extend public health to the whole country and achieve extensive PHC. The first medical school in Iran was founded by Amir Kabir during the Qajar dynasty in 1851 (called "Darol-Fonun," meaning "Polytechnic"), and the first national institution of public health (called the "House of Hygiene") began its operations in the same year, including quarantines and vaccination.

By 1921, various programs and plans including quarantines and public vaccination had been undertaken to promote health across the country. In 1939, the Maternal and Child Health Program started with establishment of the Midwifery School in Tehran (capital city of Iran). In 1940, the first nursing school was founded in Mashhad (a religious city in northeastern Iran), and the Nursing Training Program was developed to prepare specialized medical teams to serve in villages and rural areas. In the same year, the Maternal and Child Health Organization was established to support disadvantaged pregnant women by providing outpatient prenatal care and hospitalizing them for delivery and postpartum recovery. In 1941, the prevalence of syphilis and other sexually transmitted diseases triggered a campaign to fight them, although it was only implemented in Tehran due to insufficient funding.

The first ministry of health, called "Ministry of Wellbeing," was established in 1941, and the law to establish the MoHME (separating medical education from the Ministry of Higher Education and assigning it to the Ministry of Health) was passed in 1985. In 1947, a remarkable institute named "Khajenoori" was established to provide maternal and child care. This institute was affiliated with the Ministry of Wellbeing and was later named "Mother and Child health Center."

During the years, the most important concern of the governing body of the health sector has been to provide the best possible health services to the total population, including both urban and rural communities. Thus, various policy reforms and programs have been implemented in the past century to achieve this noble goal.

\section{Health Care Provision}

In Iran, at the national level, MoHME is mandated to fulfill the goal of attaining the highest level of health through governing, policymaking, planning, financing, and steering. At the provincial level, the Universities of Medical Sciences $(N=60)$ are in charge of public health, health care provision in public facilities, and medical education.

Besides the universities of medical sciences, some health care services are provided by insurance companies and the social security organizations.

The health system in Iran is organized in three levels (Figure 1). The first level provides public health and primary care services through a nationwide PHC network. The secondary level includes the district health network as the independent health authority in the district. District public hospitals as well as specialized polyclinics are located at this level. Iran also has a well-developed and active private health sector, primarily concentrated in urban areas and playing a major role in the provision of secondary and tertiary care. ${ }^{8}$

Specialty and super-specialty health care services (the third level) are mainly located in big cities. In secondary and tertiary levels of hospital care, payments are mainly made through fee-for-service and government budgets (Figure 1).

In the last seven decades, Iran has achieved significant improvements in controlling infectious diseases. A total of $9454 \mathrm{~TB}$ cases were reported in 2016. It was estimated that the actual incidence of TB cases was 12000 in the same year. From these, 350 persons were living with HIV and 200 persons were MDR/RR-TB cases. ${ }^{9}$ Over the recent 


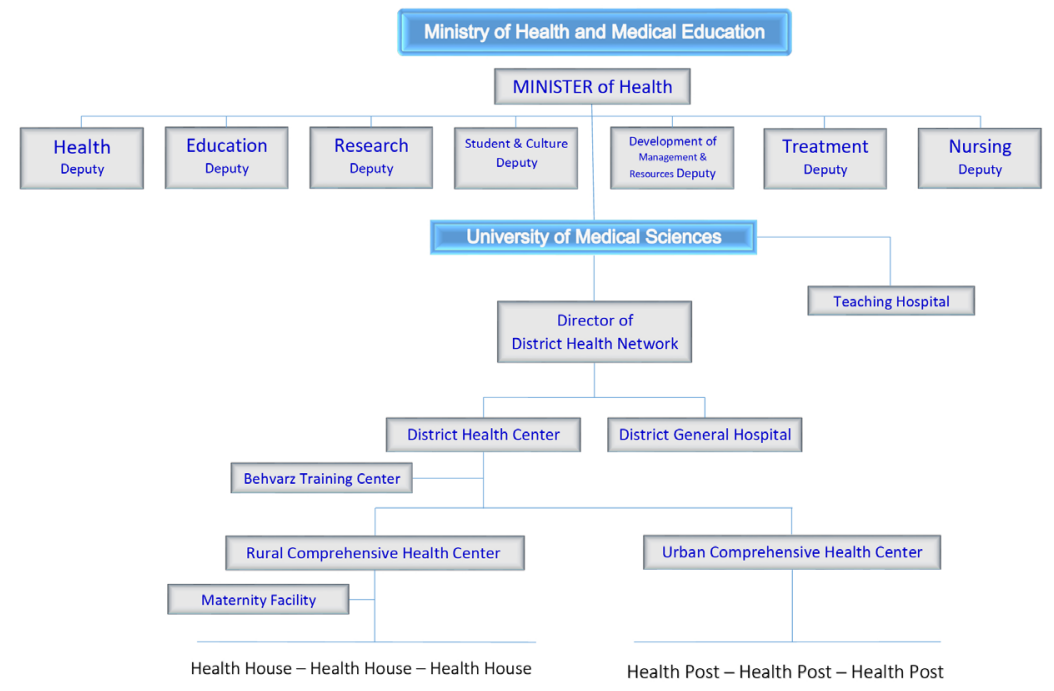

Figure 1. Health system structure in Iran.

20 years, the overall public health has improved and child mortality rate, morbidity, and maternal mortality rate have decreased dramatically. ${ }^{10,11}$ Nowadays, the burden of diseases attributable to communicable diseases is $9.7 \%$ (2012), 76.4\% for non-communicable diseases (NCDs) and $14.0 \%$ for injuries. ${ }^{9}$ Despite the achievements in the area of controlling and lowering some communicable diseases, the burden of TB has not changed much. ${ }^{12}$ The number of deaths due to tuberculosis among HIVnegative people was 3.8 in 2000 and 3.2 in 2013 (per 100000 population). ${ }^{13}$ In addition, the rate of some communicable disease like HIV has increased. In 2016, the Islamic Republic of Iran had 5000 (1400-13000) new HIV infections and 4000 (2500-6200) AIDS-related deaths. ${ }^{13,14}$ The rate of deaths due to HIV/AIDS increased from 0.5 per 100000 to 6 per 100000 population. ${ }^{15,16}$ Therefore, the Iranian health system still suffers from some challenges that should be addressed by future health plans. Despite all the policy interventions and programs implemented in previous years to ensure the achievement of health outcomes and universal health coverage, Iran's health system still has a long way to go to accomplish this goal. Tables 1, 2, 3 and 4 show Iran's health profile, World Health Profile, EMRO Health Profile and rank in the region (EMRO), respectively.

Iran's Development Plans before and after the Islamic Revolution

In Iran, like other countries, developing development plans is a process that tries to coordinate all available resources to achieve planned objectives and thereby, bring development to the country in determined times. ${ }^{17,18}$ Developing development plans in Iran has a history of nearly 70 years. Each plan has different parts such as health, culture, economy and mines, science and technology, administrative and management, social and legal. Due to the changing situation of each sector of the country, the objectives vary in different plans. The focus area is mainly dependent on the problems that are determined for each sector and the intellectual trends of actors in that sector. Before the Islamic Revolution in Iran, six development plans, also known as constructional plans, were designed. Each of the first three development plans lasted five years; the fourth development plan lasted four years, the fifth development plan lasted seven years; and the sixth plan lasted just one year. Since the Islamic Revolution, Iran has had six economic, social, and cultural development plans. After the eight years of the Iran-Iraq war (1980-1988), Iran continued designing and implementing development plans in order to achieve the determined objectives of the plan in five years.

Addressing community health needs has been one of the essential components of Iran's development plans that seek to achieve goals such as enhancing the quality of development with an emphasis on human capital and consequently, increasing productivity and reducing the vulnerability of the population to health problems. Table 5 shows multi-year development plans of Iran 1948-2017.

PHC Development during the First to Six Development Plans before the Islamic Revolution (1948-1989)

The first constructional plan (1948-1955) had no longterm orientation. It was developed as a mandate from upper level; so it faced some difficulties at launch, and less than $20 \%$ of the total projected investment took place. There is no trace of attention to public health and primary care during the implementation of this plan.

The second constructional development plan (19551962) was implemented with the goal of increasing production, growing exports, improving public health, 
Table 1. Iran's Health Profile

\begin{tabular}{|c|c|c|c|c|}
\hline \multirow{2}{*}{ Indicators } & \multicolumn{4}{|c|}{ Year } \\
\hline & 1984 & 2000 & 2015 & 2017 \\
\hline Neonatal mortality (per 1000 live births) & 51 & 29 & 9.48 & 8.9 \\
\hline Under-five mortality (per 1000 live births) & 60 & 36 & 15.5 & 14.8 \\
\hline Maternal mortality (per 100000 live births) & 140 & 37 & 21 & 18 \\
\hline Life expectancy female & 65 & 73 & 76.6 & 79.36 \\
\hline Life expectancy male & 63 & 71 & 74.5 & 75.47 \\
\hline Life expectancy both genders & 64 & 70 & 75.5 & 75.6 \\
\hline Access to rural primary care $(\%)$ & 20 & 90 & 98 & 99 \\
\hline Access to safe water $(\%)$ & 71 & 95 & 98.7 & 99 \\
\hline Number of health houses & 11000 & 16281 & 17600 & 17950 \\
\hline Vaccination coverage $(\%)$ & 20 & 95 & 99 & 99 \\
\hline Number of patients seeking care abroad & 11000 & 2000 & 0 & 0 \\
\hline Number of foreigner physicians & 3153 & 0 & 0 & 0 \\
\hline
\end{tabular}

* Source: Iran Ministry of Health and Medical Education.

Table 2. World Health Profile

\begin{tabular}{|c|c|c|c|c|}
\hline \multirow{2}{*}{ Indicators } & \multicolumn{4}{|c|}{ Year } \\
\hline & 1990 & 2000 & 2015 & 2017 \\
\hline Neonatal mortality (per 1000 live births) & 36.7 & 30.6 & 19.1 & 18.2 \\
\hline Under-five mortality (per 1000 live births) & 93.2 & 76.4 & 42.4 & 39.8 \\
\hline Maternal mortality modeled Estimate (per 100000 live births) & not found & 342 & 210 & 211 \\
\hline Life expectancy female at birth (years) & 66.321 & 69.867 & 74.272 & 74.701 \\
\hline Life expectancy male at birth (years) & 61.903 & 65.408 & 69.779 & 70.213 \\
\hline Life expectancy both Genders (total) & 64.021 & 67.549 & 71.947 & 72.373 \\
\hline Access to safe water (\%) & not found & 82.48 & 90.95 & 71 \\
\hline
\end{tabular}

Resources: World Bank, Our World in Data, WHO.

and achieving a flourishing social culture. Activities aimed at preventing poppy cultivation in the country accelerated in this time period. In 1957, a campaign for the eradication of malaria was launched with the cooperation of the WHO. ${ }^{19,20}$ During the 1962-1967 period, the third constructional development plan was developed.

Table 3. EMRO Health Profile

\begin{tabular}{lccc}
\hline \multirow{2}{*}{ Indicators } & \multicolumn{3}{c}{ Year } \\
\cline { 2 - 4 } & $\mathbf{2 0 0 0}$ & $\mathbf{2 0 1 5}$ & $\mathbf{2 0 1 7}$ \\
\hline Neonatal mortality (per 1000 live births) & 23.4 & 15.5 & 15.4 \\
\hline Under-five mortality (per 1000 live births) & 50 & 28 & 27 \\
Maternal mortality (per 100000 live births) & 158 & 126 & 84 \\
Life expectancy both genders at birth & 68 & 70.93 & 71.4 \\
\hline Access to safe water (\%) & 89 & 93.5 & 82 \\
\hline
\end{tabular}

Resources: Our World in Data, UNICEF, http://rho.emro.who.int.

Table 4. Iran's Health Profile (Rank in the EMRO Region, 2015)

\begin{tabular}{ll}
\hline Indicator & Rank \\
\hline Life expectancy at birth (years) $^{\mathrm{a}}$ & 5 \\
$\begin{array}{l}\text { Neonatal mortality rate (per 1000 live births) } \\
\text { Infant mortality rate (probability of dying by age 1 per 1000 live } \\
\text { births) }\end{array}$ & 11 \\
$\begin{array}{l}\text { Under five mortality rate (probability of dying by age 5 per 1000 } \\
\text { live births) }\end{array}$ & 11 \\
\hline
\end{tabular}

* Source: World Health Organization 2017.

${ }^{a}$ Higher rank is desirable; ${ }^{b}$ Lower rank is desirable.
This plan was the first comprehensive plan developed until then and focused on infrastructure construction and attention to education and social issues. The third plan considered employment creation, national income growth of six percent per year, and equitable distribution of income in society. The plan's performance was higher than the approved measures in agriculture, utilities, and the oil industry, but not in other industries, construction, and mines.

During the third constructional development plan, the Health Corps Law was passed by the parliament in April 1964, and the first teams of health professionals were sent to rural areas in the same year. These teams consisted of medical university graduates who served their military service as health care providers in the Ministry of Wellbeing. The teams included some high school graduates who were assigned to health houses in villages after undergoing special training.

According to a supervising committee created in 1972 to examine health care provision in the whole country, Health Corps could not fully respond to the health care needs of the rural regions after eight years of activity due to short-term services, greater focus on therapy, and lack of PHC foundations in rural areas.

The fourth constructional plan (1968-1972) 


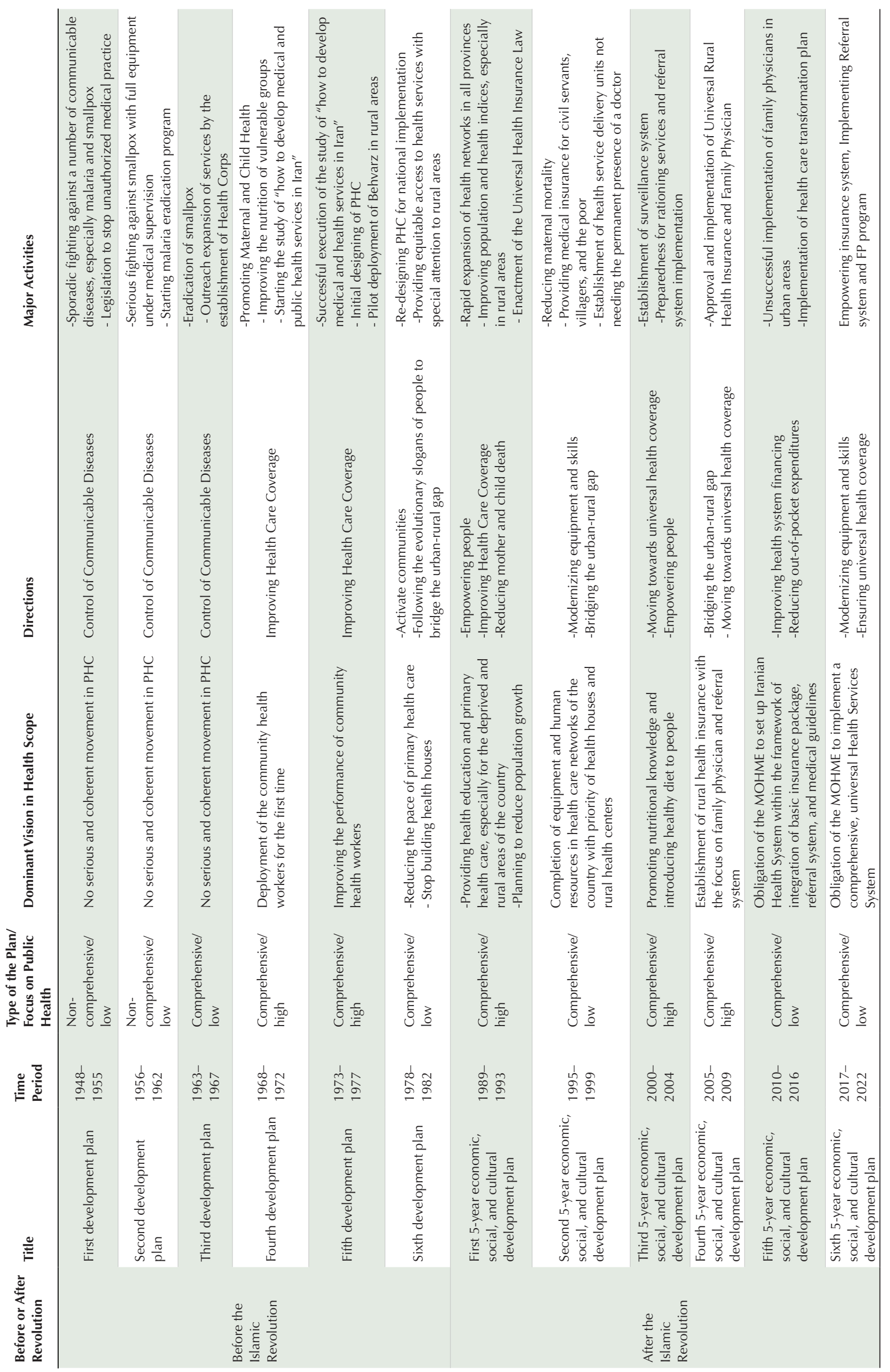


was also comprehensive and followed the issue of equitable distribution of income as the main goal. The main emphases of the plan were the construction of infrastructure and development of industries. Generally, rapid economic development through industrialization, mechanized cultivation, and import substitution were the main priorities in the fourth plan. Chapter 18 of the plan has been named "Health and Wellbeing." This chapter very briefly discussed anticipating allocation of additional income from other chapters of the plan, the private sector, and social insurance to health and wellbeing costs during the implementation of the plan. During the fourth constructional plan, a severe shortage of midwives led the Ministry of Wellbeing to initiate a Midwifery Training Program for rural regions. Another major action during the fourth plan was the establishment of rural clinics in order to provide outreach health care services. Physicians, midwives, and public health and familyplanning professionals worked in these clinics. Midwives performed normal deliveries and were supervised by physicians in dealing with gynecological conditions and labor complications.

Inspired by other countries' experiences and building on the activities that had been going on for several decades, a study titled "Development of Healthcare Services in West Azerbaijan" was conducted in 1971 with the help of the World Health Organization (WHO), the Ministry of Wellbeing, Social Services Organization, School of Public Health, and Institute of Public Health Research of Tehran University in West Azerbaijan province (this province was at an average level in terms of health care services among the 23 provinces of Iran at that time). This study aimed to evaluate the status quo of health care services and provide a model of health care services provision in villages by community health workers. The main strategy derived from this research project was to train and employ non-physician staff including health workers and public health technicians in provision of PHC services and increase availability and accessibility to the public. After the preliminary study and field preparation, the project was officially started in Chonqeraluy-e Yekan village in the central region of the province in $1972 .^{21}$

The then government established the National Health Council to design and conduct an extensive study of the problems of health care in the country. The result was three volumes containing an analysis of the status quo, views of experts, and recommendations about health services, human resources training, and other issues. ${ }^{22,23}$ In May 1973, the terms "Behvarz" (community health workers) and "primary health care" were used in the West Azerbaijan project for the first time. ${ }^{24}$

The fifth constructional development plan (1973-1977) that considered regional planning was a comprehensive one with decentralized principles. The focus was to achieve greater convergence in national income. Equitable distribution of income was of great importance in the fifth plan, as it was considered to take priority over economic growth. Attention to improving people's quality of life indirectly affected the development of primary health needs during the implementation of the plan. Establishing a correlated regional health network system and training required low-level human resources in the health sector to provide health services to rural and deprived areas of the country, and implementing a policy of free health in the country were mentioned as a letter in the plan. However, the focus in the plan was on construction and increasing the country's income.

In the health sector, along with implementation of the fifth plan, greater emphasis was placed on the use of appropriate human resources in different regions of the country. In 1974, the Training Program of rural health workers named "Behdar" (health handler) was implemented in Kavar city in Fars Province and was later extended to its other cities, including Marvdasht and Firuzabad. ${ }^{25}$ It was also implemented in Shemiranat county in Tehran, Tonekabon city in Mazandaran, and Selseleh county (Alashtar is the center of the county) in Lorestan province. In the same year, the Ministry of Wellbeing agreed with the extension of the pilot project to other districts of the province. ${ }^{26}$ In 1976, a WHO assessment team selected the West Azerbaijan project as the most appropriate and preferred model for PHC implementation in Iran. ${ }^{27,28}$

In 1977, the valuable results of the West Azerbaijan project convinced the Ministry of Wellbeing that expansion of this model to the entire country could improve health service coverage, especially in rural areas. ${ }^{21}$ Therefore, the Ministry of Wellbeing approved the official training of health workers and creation of a PHC system by establishing health houses in villages. ${ }^{29,30}$

In the same year, Behvarzes were trained for 22 provinces in addition to West Azerbaijan. Based on predictions, they could cover about four million people $(20 \%$ of the rural population) until 1979. Eventually, the last plan before the revolution was designed for years 1978 to 1982 . This plan was prepared by considering land-use planning, but stopped due to the onset of the 1979 revolution and the situation thereafter. Since the experience of the first to fifth constructional plans has been the backbone of this program, it was the most complete development plan. However, the terms of its implementation were not provided. Although the first to sixth plans were progressively more scientific and sophisticated, the executive body of the country did not adequately find the capacity to accept changes. Hence, the country could not develop a disciplined, regulated, accountable, and fundamental health infrastructure over 30 years (1948-1979).

In the first development plan, policies encouraging population control and promoting maternal and child 
care were among the priorities of the plan. On the other hand, inpatient services during this plan, poorly planned expansion of hospitals in certain sub-national regions without respecting the actual needs of the people led to empty beds and wasted resources.

PHC Development in First Decade after the Islamic Revolution (1979-1988)

In 1979, Iran underwent a revolution with fundamental changes in the country. ${ }^{24}$ Although the country had experienced improved health and demographic indicators over time, public health was very poor in the late $1970 \mathrm{~s}$ and was comparable to the poorest countries in the world. ${ }^{31}$ During eight years of the Iran-Iraq war (19801988), the development of any national development plan in the country was stopped and no plan was approved in the country.

After the Iran-Iraq war, to achieve Article 29 of the Constitution of the Islamic Republic of Iran that emphasizes the universal rights of the public to health services and medical care, the activities, various plans and programs that had started before the war were put on the agenda.

In the first decade after the revolution, Iran's health system underwent its greatest turbulence and at the same time, enjoyed its greatest success. Some health indicators, such as mortality rates started to improve during this period. The foundation of policies implemented from 1979 to late 1989 can be summarized as follows: 1) the threefold activity of health, prevention, and treatment were deemed inseparable and were unified into a single universal, interconnected framework, and 2) the importance of planning and running health care systems based on the most advanced creative management practices underlined.

In 1980, a council was established to evaluate the plans and organizational structure of the Ministry of Wellbeing. The council published its results in a book titled " $A n$ Outlook on Health, Treatment, and Medical Education" in 1981. Subsequently, the PHC network was designed and implemented based on the results of the West Azerbaijan project. In this system, maternal and child health are among the most important components of PHC, and related services are provided by urban and rural health centers and health houses. ${ }^{32}$ The Family Health Worker Training Program and Local Midwifery Training Program were two important initiatives that the Ministry of Wellbeing approved in 1983.

Building on the experiences of previous projects, the program to expand health network and stratify health care services was implemented in all Iranian cities during 1982-1987 as one of the most successful initiatives in access to health care services worldwide. Iran's PHC system is founded on the policies of maternal and child care and communicable disease control. ${ }^{33}$ To implement this plan, members of parliament approved an amendment to the proposed health budget amounting to 2.5 billion rials for expansion of the PHC (US\$1.00 = 580 Rial in March 1985). ${ }^{34}$ In the first year of implementation, one city from each province was covered by the PHC system expansion plan, and the plan would continue if the experience was successful. The program happened to be very successful and was approved by the parliament and the public. Therefore, necessary funds were allocated to extend the PHC to all cities in all provinces.

Thus, the PHC network was implemented in 1985 and gradually extended to all provinces. This improved the country's health care system and enhanced the general state of health. ${ }^{35}$ Special focus was put on vulnerable age groups and women, and on meeting the basic needs of disadvantaged populations, especially those living in rural areas, and providing a successful model of $\mathrm{PHC}$ implementation. ${ }^{32}$ Intelligent actors, clear policy content, and objectives agreed by policymakers were the most important factors that led to the implementation of the health care network in a specific socioeconomic context. ${ }^{36,37}$

Along with the expansion of the PHC, a set of policy interventions aimed at socioeconomic development were conducted that lead to considerable progress in educational infrastructure and quality of life, ${ }^{33}$ and significant improvement in Iran's public health and mortality rate. ${ }^{38,39}$

In 1984, there were about 1800 health houses and 2400 health centers across the country, and many rural regions and small towns were deprived of PHC services. In 1989, four years after the PHC network started its activities, significant changes were made in the number and distribution of government facilities, through increasing the number of health houses to more than 7900 and the number of health centers to more than $4300 .{ }^{21}$ Iran is one of the few countries that have achieved Millennium Development Goals 4 and 5 in reducing maternal and child mortality rates by $2015 .^{40,41}$

In 1988, "Vital Horoscope" was introduced into health houses as a data collection mechanism. It is a chart for recording vital information such as vital events including births and deaths as well as family-planning activities within the community. Age and sex distribution, maternal mortality, and other indicators are also recorded. Each page of the chart is devoted to data from one year. ${ }^{42}$

Increasing expansion of PHC coverage in rural regions with the help of Behvarzes in health houses quickly filled the gap between cities and villages in availability of health care services. ${ }^{43,2}$

The Expanded Program on Immunization (EPI) in Iran started as a vertical project in early 1984 and developed during this period, but during program expansion, gradually integrated into the PHC network activities. ${ }^{44,45}$ Implementation of this program increased vaccination coverage from $40 \%$ (1995) to $99 \%$ (2016). ${ }^{46}$ Many actors 
in the health system consider the significant reduction in child mortality to be the result of implementing EPI in the country. ${ }^{44,46}$

Moreover, owing to the establishment of the PHC network, support to families in terms of oral rehydration for acute diarrhea was fast and extensive. ${ }^{46-48}$ The most noticeable change in life expectancy at birth occurred between 1986 and 1990, when the PHC expansion program was implemented nationwide. ${ }^{21,35}$

In 1985, the MoHME was established, and the Ministry of Wellbeing and Welfare turned into the new Ministry. Establishment of health houses significantly decreased physicians' workloads in health centers. An even greater decrease would be expected with an efficient referral system, but this was not achieved at any time during the extension of the PHC system. ${ }^{24,33}$

Concurrent with the Rural Midwifery Training program in 1990, a program was proposed to construct birthing centers. It was approved by the parliament and was implemented to minimize the risks of deliveries performed by traditional midwives.

PHC Development during the First to Six Development Plans after the Islamic Revolution (1989-2018)

Second Decade after Revolution (1990-2000)

After the Iran-Iraq war, the first social, economic, and cultural development plan (1989-1993) was implemented with the campaign of economic liberalization. The main goal of this plan was to change the negative economic trends in favor of economic growth in the country and provide a platform for future growth by investing the government in the reconstruction and renovation of the war-damaged areas and maximum utilization of the existing capacities. Therefore, the first development plan was focused on constructions. However, efforts to achieve social justice had been listed in this plan's objectives, but in practice, on this issue, there is no related article even in the narrow sense. Most of the issues in this plan were related to the supportive affairs of health and wellbeing.

In 1995, the second development plan was passed in three chapters by the parliament. In this plan, the strategy was to consolidate the achievements of the first development plan, stabilize the economic trend of the country, and reduce the economic burden of changes to society. There is no difference between this plan and the first plan in terms of structure and nature. The second plan was based on economic liberalization and privatization. Social security was highlighted in this plan, and extension and improvement were taken into consideration. Furthermore, social insurance development was considered specifically.

In 1995, the Medical Services Insurance Organization (MSIO) was established to provide health insurance to government employees, the poor, the peasants, selfemployed individuals, and other social groups. ${ }^{49}$
Since 1996, urban health centers were incorporated into the PHC network to provide maternal and child care, promote environmental health, prevent or fight off diseases, and provide other health services in suburban areas without the need for a physician.

Third Decade after the Islamic Revolution (2000-2010)

The parliament approved the third Economic, Social, and Cultural Development plan (1999-2003) in 1999, which became famous as a structural reform plan. The main direction of the third, plan like the previous plan, was to achieve liberalization and privatization through structural and fundamental reforms. From the beginning of the third development plan, the approach shifted toward delegation of services and distributive justice. Policies aimed at reducing incumbency advantages and organizing the health care system through service rationing and PHC network program are significant outcomes of the third development plan.

In the supporting documents of this plan, extending the social security system with the focus on targeted support policies was mentioned as the objective of the plan. In the third development plan, reduction of maternal mortality was underlined under the birth control policy. ${ }^{50}$

In 2002, a team of professionals from MoHME, MSIO (with an estimated 35\% insurance coverage), Social Security Organization (SSO, the largest public insurance company mainly covering wage-earners and salaried employees), the former Organization of Management and Planning (responsible for setting annual budgets), and the Parliamentary Committee on Health was assigned to study and evaluate PHC in different areas. During the study phase, the team concluded that providing health care services through the family physician (FP) program was an effective strategy for improving the quality of services, reducing costs, and minimizing inequality in the provision of health care as recommended by the WHO. ${ }^{51}$

In 2008, based on international health organizations like the WHO, an approach was adopted that centered on the FP program and priority of $\mathrm{PHC}$ over specialized services. Legal support contributed to the formation of this plan. Article 193 of the third development plan mentions rationalization of health services as a factor in balanced supply and distribution of inpatient services proportionate to public health needs in different regions of the country.

According to most experts and based on the experiences of various countries, the FP program, rationalization of health care services, and referral system are the main solutions for many of the challenges in provision of health care services. ${ }^{52}$

The FP and the referral system were successfully incorporated into the fourth economic, social, and cultural development plan (2004-2009). This five-year development plan was approved by the Majlis (Parliament of Iran) in 15 chapters and 161 articles. 
In the fourth development plan, the top priorities were to reduce health risks, enhance food security, increase responsiveness to non-medical needs of the community, and achieve fair distribution of health care services. In addition to delegation of services to the private sector, concepts such as justice in health care and goal-setting for reduction of household catastrophic health expenditure entered Iran's laws.

The formulation and approval of the plan in the light of Iran's 20-year perspective document (as a national upstream plan) were the main characteristics of the fourth development plan. The planning system of this plan, unlike previous plans, tried to integrate and coordinate this plan with the yearly budget.

In the fourth development plan, like other plans, the issue of extending social insurance was considered. In 2005, MSIO was asked to provide insurance for all residents of villages and cities with a population of under 20000 to make health care services available to them. ${ }^{8} \mathrm{MoHME}$ used this opportunity to establish the FP and referral system. Since the implementation of the FP program, villagers' access to physicians has increased, and physicians have become responsible for the public health of the covered population. ${ }^{53}$ The results of many studies show increased accessibility of health care services in villages and small cities. ${ }^{10,11,54,55}$ The existence of the PHC network played a significant role in the establishment of the FP program and acted as a platform for its implementation. ${ }^{33}$

In less than three years, about 21 million people were covered by the rural FP program and 6600 physicians and 4600 midwives started working in rural health centers, of which 2856 physicians and 3612 midwives came from the private sector. ${ }^{56}$

Fourth Decade after the Revolution (2010-Present) The fifth Economic, Social, and Cultural Development Plan (2010-2015) was passed in 2009 by the Iranian Majlis. In the fifth development plan, many of the concepts like equity in health care and reduction of household health care expenditure were reiterated. In particular, the attempt to separate private and public sectors is a significant challenge. Another important aspect of the fifth development plan is the focus on integration of health insurance organizations, which has not yet been fully achieved. ${ }^{57,58}$

Following the implementation of the FP program, the need for revision, completion, and extension of the plan throughout the country was underlined in the fifth plan by the government and policymakers, and its nationwide implementation was put on the agenda. In 2010, the FP program was implemented as a pilot project in some cities with populations of under 50000 (three provinces). ${ }^{59}$ Based on Article 32 of the fifth development plan, it was decided that a "comprehensive health care system" be designed and implemented based on PHC and with a focus on FP, rationalization of health service, and strategic purchasing of services. Thus, placing a greater emphasis on these determinants facilitated the process of achieving the goals of the plan, increasing the accessibility of health services, improving responsiveness in the health market, saving costs by reducing unnecessary medical services, increasing health insurance coverage, improving public health, and increasing fair distribution of health care in society.

From 2004 to 2012, Iran underwent other important transformations in the health system, including establishment of the Supreme Council of Health Insurance and implementation of the pilot project of rural insurance (the rural FP program). During this period, the focus has been on optimal provision of quality services and reinforcement of the referral system, all at the rural level.

In 2012, MoHME and the Ministry of Welfare and Social Security developed and published a joint guideline, aiming to extend the FP program and the referral system to urban regions of the country. ${ }^{8,53}$ However, pilot implementation of the program was limited to two provinces (Fars and Mazandaran) due to administrative problems and lack of enough funds. ${ }^{59}$

Finally, in 2014, the government took an important step in moving to achieve universal health coverage by implementing the reform called Health Transformation Plan (HTP) with the aim of reducing out-of-pocket payments (OOPs) and increasing the quality of health care services. In the first phase, the plan was implemented in a hospital-based setting through nine interventions. Four months after the first implementing phase, the plan was extended to the PHC setting. In the shadow of the reform in this setting, at present, the FP program and referral system are put on the agenda to promote public health care and achieve the goals of Iran's 20-Year national vision to 2025. During the implementation of the HTP, the Public Health Deputy of MoHME approved and implemented 15 national programs and 10 supportive projects. Through these programs, for the first time, the public-private partnership was formed in a PHC setting. ${ }^{53}$ Due to the inpatient referral process, the urban FP program started in cities with populations under 100000 and in suburban areas.

With the launch of the HTP in 2014, there was a serious move to reduce out-of-pocket payments in hospital services that showed its effectiveness in reducing OOPs in public hospital care services. ${ }^{60,61}$ But in the recent two years, there has been much fluctuation in OOPs due to the country's economic conditions, including foreign sanctions and domestic healthcare financing of the HTP.

In the HTP, emphasis has been placed on preventing and controlling NCDs, modifying nutritional patterns and controlling the risk factors of NCDs. But the PHC 
does not have all the tools needed to do this because a significant portion of outpatient curative activities is provided by the private sector, and this part does not have much commitment to NCDs control programs. The MoHME has begun a universal move towards the establishment of an electronic medical record and in the public sector, almost all health service centers are connected to this system. But the private sector, including inpatient and outpatient care, has not been linked to this system.

On March 4, 2017, one year after finishing the fifth 5-year development plan, the sixth 5-year Economic, Social, and Cultural Development plan was approved. The start of this plan was approximately concurrent with the starting the twelfth government with new initiatives and policies. Following the principles and provisions of the previous plan, the MoHME has been obliged to implement a "Comprehensive and Universal Health Services System" with the priority of PHC and preventive activities over curative, and with a focus on implementation of the FP program and establishing a referral system in the whole country. Tables 6 and 7 summarize the stages of PHC development in Iran, time period and collaborators and the historical evolution of structural interventions and causes in PHC.

\section{Discussion}

This study explains the history of PHC development in the light of Iran's development plans as upper-level policy documents before and after the Islamic revolution. The PHC history explained in this study indicates that the country's PHC network has been founded on the policy of controlling communicable diseases and improving maternal and child health care. ${ }^{62}$ During the first to fourth development plans before the revolution, various efforts were made to establish a health care system especially in rural areas and small towns. The first major program began in the 1940s under the name of "Behdar " training project. The other main program was the enactment of
"Health Corps" law in the early $1960 \mathrm{~s}^{21,28}$ which had a pivotal effect on extending public health in the country in that time period.

In all those years (first to sixth five-year development plans), although the Imperial Organization for Social Services provided services in various parts of the country, including rural areas, due to scattered and non-cohesive service provision, that organization could not provide adequate healthcare coverage, and its activities did not have the proper effect on public health.

In the 1970s, several projects were implemented, including the West Azarbaijan project, Kavar Project (rural health worker training in Fars province) and the projects of Lorestan and Tehran provinces. According to an assessment by the WHO in 1976, the model of West Azerbaijan was the most successful project to provide PHC in Iran. ${ }^{28,63}$

At the same time as the pilot stage of the West Azarbaijan project, the "Commission on the Study of Health and Medical Problems of Iran" was formed. The results of the commission's reviews were published in the form of three books called "A route to well-being" which were effective in selecting West Azarbaijan project as the most suitable project for providing PHC services. But the comprehensive PHC network was not formed until the 80 s, and it was implemented with full government authority and its financial support. ${ }^{21,29}$

In pre-revolutionary development plans, as well as in the first and second development plans after the revolution, poor public awareness and low scientific-executive capacity outside the public sector forced government to intervene and implement plans and strategies using its employees to reach the determined goals. Today, we are facing demographic and epidemiological transitions and the incidence rate of NCDs is increasing, so the types of needs and expectations of people have changed and the existing healthcare system cannot meet the new requirements. This reality, along with technological advances in production and service provision, increased exchange of medical

Table 6. Stages of PHC Development in Iran, Time Period and Collaborators

\begin{tabular}{llll}
\hline PHC Development Stage & Time Period & Main Responsible Organizations & Other Collaborators \\
\hline $\begin{array}{l}\text { Design and implementation of West Azerbaijan Project } \\
\text { (Pilot study) }\end{array}$ & $1971-1976$ & $\begin{array}{l}\text { SPH \& IPHR. IPHR's Health } \\
\text { Research Station in Urmia }\end{array}$ & $\begin{array}{l}\text { WHO, MOH, Health care delivery } \\
\text { organization in West Azerbaijan }\end{array}$ \\
$\begin{array}{l}\text { Primary acceptance of West Azerbaijan pilot as a country } \\
\text { plan }\end{array}$ & $1976-1978$ & Ministry of Health and Welfare & Other governmental sectors \\
$\begin{array}{l}\text { Redesigning and planning for expansion of plan at country } \\
\text { level }\end{array}$ & $1981-1984$ & Ministry of Health and Welfare & Other governmental sectors \\
$\begin{array}{l}\text { Expansion of PHC network in entire country } \\
\begin{array}{l}\text { National implementation of rural insurance plan and rural } \\
\text { family physician plan }\end{array}\end{array}$ & $2005-2011$ & MoHME & Majlis \\
$\begin{array}{l}\text { Implementation of urban family physician plan as a pilot } \\
\text { plan }\end{array}$ & $2012-2014$ & $\begin{array}{l}\text { Mazandaran and Shiraz } \\
\text { Implementing transformation plan in PHC }\end{array}$ & 2014 until now \\
\hline
\end{tabular}


Table 7. Historical Evolution of Structural Interventions and Causes in PHC

\begin{tabular}{|c|c|c|}
\hline Year & Intervention & Cause \\
\hline 1851 & Opening the first medical education course in Darol-Fonun academy & Training of medical staff needed in the country \\
\hline 1881 & Forming Health Preserver Assembly & Founding measures in the field of public health \\
\hline 1881 & Establishing the first medical school & Training of medical staff needed in the country \\
\hline 1923 & Establishing the "Red Lion and Sun Society" & The development of health services in specific areas \\
\hline 1924 & Opening Pasteur Institute & $\begin{array}{l}\text { The development of medical basic research and production of } \\
\text { vaccines and serums }\end{array}$ \\
\hline 1926 & Forming Public health department in the Ministry of Interior & Addressing the health affairs of the population \\
\hline 1935 & Forming Iranian department for health & Continuing the activities of public health department \\
\hline 1940 & $\begin{array}{l}\text { Opening the first practical nurse school in Mashhad in the form of "health officer } \\
\text { training" plan }\end{array}$ & Training medical staff to serve in rural areas \\
\hline 1941 & Establishing "Ministry of Wellbeing" & $\begin{array}{l}\text { Development of the country's organization and management to } \\
\text { address public health issues }\end{array}$ \\
\hline 1945 & Opening paramedic school & Training medical staff to serve in the medical care units \\
\hline 1947 & Establishing the Imperial Organization for Social Services & $\begin{array}{l}\text { Provision of medical, social, and health services to help the } \\
\text { disadvantaged people }\end{array}$ \\
\hline 1949 & Starting physicians' two-year service plan outside Tehran & $\begin{array}{l}\text { Service provision for towns and villages deprived of medical } \\
\text { staff }\end{array}$ \\
\hline 1949 & Establishing Ashraf Pahlavi Nursing Academy & Providing nurses for hospitals, particularly in deprived areas \\
\hline 1957 & Starting malaria eradication program & Testing a control system for one of the most common diseases \\
\hline 1963 & Opening the Institute of Health Research & Research extension to support health activities \\
\hline 1964 & Health Corps Law enforcement & Supplying medical staff for rural areas \\
\hline 1964 & Declaration of smallpox eradication & The first result of successful health policies \\
\hline 1966 & $\begin{array}{l}\text { Founding the first School of Public Health by combining the Department of } \\
\text { Health Sciences, Medical School, Tehran University, Institute of Health Research, } \\
\text { and } \mathrm{MOH} \text { hospital management programs }\end{array}$ & Integrated development of health science education \\
\hline 1971 & $\begin{array}{l}\text { Pilot implementation of primary health care services in West Azerbaijan after a } \\
\text { formal agreement between the Ministry of Health, the University of Tehran, and } \\
\text { the WHO }\end{array}$ & $\begin{array}{l}\text { Training community health workers and equitable distribution of } \\
\text { services throughout the country, especially in deprived areas }\end{array}$ \\
\hline 1971 & Establishment of villagers' social security organization & $\begin{array}{l}\text { Providing equitable health care financing for part of the } \\
\text { country's population }\end{array}$ \\
\hline 1973 & Expansion of equitable primary health care across the country & $\begin{array}{l}\text { Providing nationwide services of primary health care, especially } \\
\text { in deprived areas }\end{array}$ \\
\hline 1973 & $\begin{array}{l}\text { Launching health services network and training auxiliary health staff (Behvarz } \\
\text { training centers) }\end{array}$ & $\begin{array}{l}\text { Providing community health workers (Behvarz) in the shortest } \\
\text { possible time }\end{array}$ \\
\hline 1974 & The proposal to integrate medical education and service delivery systems & $\begin{array}{l}\text { Conformity of training programs with the needs of the service } \\
\text { provider network }\end{array}$ \\
\hline 1976 & Formation of Ministry of Health and Welfare & $\begin{array}{l}\text { The provision of health and social welfare, rehabilitation } \\
\text { services, family planning, and addressing population issues }\end{array}$ \\
\hline 1976 & Formation of regional health organizations in provinces & $\begin{array}{l}\text { The first formal health care organization in the country with } \\
\text { financial and administrative powers }\end{array}$ \\
\hline 1977 & $\begin{array}{l}\text { Deploying local health workers to deliver primary health services - Creation of } \\
\text { PHC network }\end{array}$ & Providing the required staff for health units by indigenous people \\
\hline 1982 & $\begin{array}{l}\text { Designing health network by the integration of health services and medical } \\
\text { education }\end{array}$ & $\begin{array}{l}\text { Qualitative and quantitative development of health services - } \\
\text { expansion of community-based medicine }\end{array}$ \\
\hline 1985 & $\begin{array}{l}\text { Establishment of Ministry of Health and Medical Education after separation of } \\
\text { medical education from the Ministry of Culture and Higher Education }\end{array}$ & $\begin{array}{l}\text { Integration of medical education with health delivery system by } \\
\text { taking a few principles: } \\
\text { Prioritizing prevention over treatment } \\
\text { Community-based education } \\
\text { Prioritizing outpatient over inpatient treatment } \\
\text { Prioritizing addressing underserved areas }\end{array}$ \\
\hline 1988 & Integration of regional health organizations with University of Medical Sciences & $\begin{array}{l}\text { Alignment of provincial health structure with ministry } \\
\text { headquarters }\end{array}$ \\
\hline 1990 & Enactment of the Health Messengers law & Improving service delivery to disadvantaged areas \\
\hline 1994 & Enactment and communication of Universal Health Insurance Law & Increasing people's access to services with sustainable financing \\
\hline 1995 & $\begin{array}{l}\text { Formation of Medical Insurance Organization and Supreme Council of Medical } \\
\text { Insurance }\end{array}$ & Full coverage of population by medical insurance organizations \\
\hline
\end{tabular}


Table 7. Continued

\begin{tabular}{lll}
\hline Year & Intervention & Cause \\
\hline 1999 & $\begin{array}{l}\text { Modifying the organizational structure of the Ministry of Health } \\
\text { Implementation of rationing of inpatient treatment services }\end{array}$ & $\begin{array}{l}\text { Improving levels of decision-making and avoiding task } \\
\text { interference } \\
\text { Increasing people's access to general and specialized health } \\
\text { services around the country }\end{array}$ \\
2004 & $\begin{array}{l}\text { Approval of the law of comprehensive system of welfare and social security } \\
\text { Establishment of the Ministry of Welfare and Social Security (medical insurance } \\
\text { and social security organizations entrusted to it) }\end{array}$ & $\begin{array}{l}\text { Universal insurance coverage and increasing horizontal and } \\
\text { vertical equity } \\
\text { Improving access to health services }\end{array}$ \\
2005 & $\begin{array}{l}\text { Implementation of pilot program for rural insurance } \\
\text { Implementing the plan for insuring patients on the hospital bed }\end{array}$ & $\begin{array}{l}\text { Strengthening health care delivery network } \\
\text { Providing the basics of family physician program }\end{array}$ \\
\hline 2014 & $\begin{array}{l}\text { Formation of Health Insurance Organization and Supreme Council of Health } \\
\text { Insurance }\end{array}$ & $\begin{array}{l}\text { Universal insurance coverage and increasing horizontal and } \\
\text { vertical equity }\end{array}$ \\
& $\begin{array}{l}\text { Initiation of Family Physician program in towns and suburbs } \\
\text { Public access to services, especially in remote and low-income } \\
\text { classes }\end{array}$ \\
Reducing people's share of health care costs
\end{tabular}

information, higher public awareness, and greater private sector capability have increased the accountability of the government in response to the health needs of population. So, the government needs to focus more on policy making and monitoring functions and to guide the private sector using clear-cut criteria and standards.

After Iran's revolution, since the second five-year development plan, the focus has been on extension of public health and population control. The Iranian PHC network in the outpatient sector, especially in rural areas, has offered decent services that continue to be free of charge. But the proportion of health spending paid out of pockets in the inpatient sector has been high for most people (urban and rural), and has pushed the government to plan for health transformation.

This problem, along with other challenges facing the health sector today (i.e., the same challenges as before, but more demanding), including the evolving needs and demands of the people and population changes, necessitate reform of the structure of the PHC network as the main mission of the MoHME.

Providing health care services through the FP program has been emphasized in the third to sixth development plans after the revolution and has been agreed upon by policy makers as an effective strategy for improving quality of services.

In 2011, a serious decision was made to implement the FP program throughout the country. But inadequate governmental support and lack of compliance with the program by various stakeholders and lack of required infrastructures including structural, technical and informational, prevented the successful implementation of the program..$^{21,59}$

Bridging the gap between urban and rural areas and social justice were among the principal slogans of the Islamic Revolution, which were manifested in the form of popular demands..$^{32}$ In the early 1980s, lack of health infrastructure, especially in rural areas, led the government to establish health care networks. ${ }^{64}$ About 20 years later, in 2005 , a shortage of doctors and other health workers in rural areas led to the development of the FM program. ${ }^{65}$ It is explainable by the theory of social change ${ }^{66,67}$ that is defined as follows, "the policy tries to remove the public problem in case of public request." This presumes interplay between decisions and activities that allocate values. ${ }^{68}$ The values referred to are usually determined by the community that emerge in the form of public demands. According to this theory, public demands can have an impact on policy formulation and implementation and even eliminate the gap between policy making and policy implementation. ${ }^{67}$

Undoubtedly, expanding the network of PHC providers and PFs in suburban areas and other rural centers can help promote family medicine dialogue in the country. It is a thought-provoking reality that in certain periods of the country's development plans, qualitative and quantitative development of the health care system has been notably fast. For example, PHC network formation and its expansion to achieve nationwide coverage took place in less than one decade.

To define "policy", John (1998) said, "... the interplay between institution, interests, and ideas" ${ }^{69}$ There is no doubt that the underlying conditions of the country have had a significant impact on this issue. However, interests and ideas of the key players along with underlying factors have caused such a rapid development.

The key actors of the Iranian healthcare network (Drs. Cyrus Pileroudi, Kamel Shadpour and Ayyub Espandar) had gained similar attitudes and interests due to work in the Health Corps and involvement in some health care programs. $^{70}$

After the Islamic Revolution, they found an opportunity to sum up their experiences in the field of public health and 
PHC and document them to transfer to administrators. ${ }^{71}$ Although those people were in different positions at the time of network design, their old friendship and common views caused an intimate relationship. So, in activities related to the health care network design and implementation, the best possible cooperation took place. This can be explained by the "advocacy coalitions" theory, propounded by Sabatier and Jenkins-Smith. ${ }^{72,73}$ Advocacy coalitions are recognized through common beliefs and policy objectives. ${ }^{74}$ They can act as influential bodies in agenda setting. ${ }^{75,76}$

Health issues are interrelated and even affected by social conditions. More physicians, extra funds, and new hospitals with more beds are not as effective as extending $\mathrm{PHC}$ and promoting the concept of prevention in solving the problems that people face today. The health system must be viewed as a whole made up of various interconnected parts. ${ }^{77}$ Its goals should be clarified, its requirements, resources, and limitations must be specified, and a systems approach needs to be adopted to solve the problems of the health system by taking into account all the contributing factors. ${ }^{78,79}$

As a result of continuation of the PHC network, the health system witnessed a remarkable success in achieving the goals of Iran's development plans, especially fair distribution of resources and provision of health care services in many parts of the country. ${ }^{53,80}$ However, the health sector is faced with serious challenges; on the one hand, epidemiological transition and demographic changes, including fast-growing urbanization, and increasing migration from villages to cities, and on the other hand, increased public awareness and health literacy, increasing demands, and limited resources. These challenges threaten our past achievements.

Overall, factors affecting PHC are not limited to certain public health variables; demographic, social, and financial variables are also influential. Thus, in studying the current health situation, in addition to the status quo related to the public health indicators, it is useful to study the current status of macro variables influencing these indicators. Demographic trends are closely related to the country's future population health. In addition to the influence of population aging on demographic indicators, it affects related health programs that can be due to the declining fertility rate along with increasing life expectancy.

\section{Conclusion}

In recent years, Iran has tried to extend public health to the whole country and achieve extensive PHC, but the attitude of policymakers was not matched by the number of interventions toward this important issue.

By analyzing the experiences of Iran's health system in the past seven decades and by understanding the status quo, the strengths and weaknesses of the system can be identified, and the systems approach needs to be adopted to develop and implement new policies.

Adherence to the guiding principles of a comprehensive health system, implementation of an all-inclusive PHC, issues related to training human resources, the role of government and the MoHME in providing health services, and the basic needs of the health system are the most important factors that require more attention for further development of health care at different levels of Iran's health system. Clarification of health policies, or, in other words, key and ideal health-related choices, allows for more rigorous pursuit of the fundamental goals of the health system.

During the last decades, Iran's health system has acted successfully in PHC although some interventions have been parallel and repetitive and sometimes contradictory that implies no definite direction in the Iranian PHC system.

\section{Authors' Contribution}

LD conceived, designed and supervised the study. LD also collected and analyzed the data and drafted the manuscript. EM conducted data collection and data analysis and contributed in drafting tables and the figure. FF commented on intellectual development of the manuscript. All authors read and approved the final draft.

\section{Conflict of Interest Disclosures}

None declared.

\section{Ethical Statement}

This study is a historical review and does not need ethical approval.

\section{References}

1. World Health Organization and Unicef, Primary health care: report of the International Conference on Primary Health Care, Alma-Ata, USSR, 6-12 September 1978.

2. Rahnema $\mathrm{H}$. The role of frontline health workers. WHO Chron. 1975;29(1):6-9.

3. Bennett S, George A, Rodriguez D, Shearer J, Diallo B, Konate $\mathrm{M}$, et al. Policy challenges facing integrated community case management in Sub-Saharan Africa. Trop Med Int Health. 2014;19(7):872-82. doi: 10.1111/tmi.12319.

4. Perry HB, Zulliger R, Rogers MM. Community health workers in low-, middle-, and high-income countries: an overview of their history, recent evolution, and current effectiveness. Annu Rev Public Health. 2014;35:399-421. doi: 10.1146/annurevpublhealth-032013-182354.

5. Zhang D, Unschuld PU. China's barefoot doctor: past, present, and future. Lancet. 2008;372(9653):1865-1867. doi: 10.1016/ S0140-6736(08)61355-0.

6. Rosenthal MM, Greiner JR. The Barefoot Doctors of China: from political creation to professionalization. Hum Organ. 1982;41(4):330-41. doi: 10.17730/humo.41.4.h01v12784j114357

7. Van Lerberghe W. The world health report 2008: primary health care: now more than ever. World Health Organization; 2008.

8. Khayatzadeh-Mahani A, Takian A. Family physician program in Iran: considerations for adapting the policy in urban settings. Arch Iran Med. 2014;17(11):776-8. 
9. World Health Organization. Global tuberculosis report. Switzerland: WHO; 2017.

10. Jabbari Beyrami H, Doshmangir L, Ahmadi A, Asghari Jafarabadi M, Khedmati Morasae E, Gordeev VS. Impact of rural Family Physician programme on maternal and child health indicators in Iran: an interrupted time series analysis. BMJ Open. 2019;9(1):e021761. doi: 10.1136/ bmjopen-2018-021761.

11. Jafari F, Eftekhar H, Pourreza A, Mousavi J. Socio-economic and medical determinants of low birth weight in Iran: 20 years after establishment of a primary healthcare network. Public Health. 2010;124(3):153-8. doi: 10.1016/j.puhe.2010.02.003.

12. Habibzadeh $F$. The control of non-communicable diseases in rural Iran. Lancet. 2012;379(9810):6-7. doi: 10.1016/S01406736(11)61678-4.

13. World Health Organization. The global health sector strategy on HIV. WHO; 2014.

14. Askarian M, Mansour Ghanaie R, Karimi A, Habibzadeh F. Infectious diseases in Iran: a bird's eye view. Clin Microbiol Infect. 2012;18(11):1081-8. doi: 10.1111/1469-0691.12021.

15. Lankarani KB, Alavian SM, Peymani P. Health in the Islamic Republic of Iran, challenges and progresses. Med J Islam Repub Iran. 2013;27(1):42-9.

16. Moghadam Moghadam MN, Sadeghi V, Parva S. Weaknesses and challenges of primary healthcare system in Iran: a review. Int J Health Plann Manage. 2012;27(2):e121-31. doi: 10.1002/ hpm.1105.

17. Rajabi F, Esmailzadeh $\mathrm{H}$, Rostamigooran N, Majdzadeh $\mathrm{R}$, Doshmangir L. Future of health care delivery in iran, opportunities and threats. Iran J Public Health. 2013;42(Suppl 1):23-30.

18. Karadimitriou N. Planning policy, sustainability and housebuilder practices: The move into (and out of?) the redevelopment of previously developed land. Prog Plann. 2013;82(100):1-41. doi: 10.1016/j.progress.2012.10.001

19. Sadrizadeh B. Malaria in the world, in the eastern Mediterranean region and in Iran: review article. WHO/ EMRO Report; 2001:1-13.

20. Edrissian G. Malaria in Iran: Past and present situation. Iran J Parasitol. 2006;1(1): 1-14.

21. Moshiri E, Rashidian A, Arab M, Khosravi A. Using an analytical framework to explain the formation of primary health care in rural Iran in the 1980s. Arch Iran Med. 2016;19(1):16-22.

22. de la Santé OM. Primary health care: report of the International Conference on Primary Health Care, A.-A., USSR, 6-12 September 1978: WHO; 1991.

23. Verulava T. Health Care System in the Islamic Republic of Iran. Insurance, Health Policy \& Management. 2006. Available from: http://eprints.iliauni.edu.ge/1676/1/Health_Care_ System_in_the_Islamic_Republic_of_Iran.pdf. Accessed 2 Oct 2019.

24. Shadpour K. Primary health care networks in the Islamic Republic of Iran. East Mediterr Health J. 2000 Jul;6(4):822-5.

25. Zeighami E, Zeighami B, Javidian I, Zimmer S. The rural health worker as a family planning provider: a village trial in Iran. Stud Fam Plann. 1977;8(7):184-7.

26. Ronaghy HA. Kavar village health worker project. J Trop Pediatr Environ Child Health, 1978;24(1):13-60.

27. Malekafzali H. Primary health care in the rural area of the Islamic Republic of Iran. Iran J Public Health. 2009;38(Suppl 1):69-70.

28. Bahadori M. Medical Care and Education in Iran. JAMA. 1975;232(9):2.

29. Danaei G, Farzadfar F, Kelishadi R, Rashidian A, Rouhani OM, Ahmadnia S, et al. Iran in transition. Lancet. 2019;393:19842005. doi: 10.1016/S0140-6736(18)33197-0.

30. Tavassoli M. Iranian health houses open the door to primary care. Bull World Health Organ. 2008;86(8):585-6. doi:

\subsection{1/blt.08.030808}

31. Lankarani K. Health in Iran; 40 Years After the Islamic Revolution. Arch Iran Med. 2019;22(7):403-409.

32. Mehryar A. Primary health care and the rural poor in the Islamic Republic of Iran. Asia and Pacific Population Studies Centre, Ministry of Science and Technology: Tehran; 2004.

33. Takian A, Doshmangir L, Rashidian A. Implementing family physician programme in rural Iran: exploring the role of an existing primary health care network. Fam Pract. 2013;30(5):551-9. doi: 10.1093/fampra/cmt025.

34. Pileroudi C, Vassigh A, UNICEF. The district primary health care networks in Iran. National Library of Iran; 2002.

35. Aghajanian A, Mehryar AH, Ahmadnia S, Kazemipour S. Impact of the rural health development programme in the Islamic Republic of Iran on rural-urban disparities in health indicators. World Hosp Health Serv. 2008;44(3):10-5.

36. Walt G, Gilson L. Reforming the health sector in developing countries: the central role of policy analysis. Health Policy Plan. 1994;9(4):353-70.

37. Crow DA. Policy entrepreneurs, issue experts, and water rights policy change in Colorado. Revi Policy Res. 2010;27(3):299315.

38. Khosravi A, Taylor R, Naghavi M, Lopez AD. Differential mortality in Iran. Popul Health Metr. 2007;5:7.

39. Malekafzali $\mathrm{H}$. Primary health care in the rural area of the Islamic Republic of Iran. Med Sci Monit. 2009;15(5):PH32-6.

40. Zolala F, Heidari F, Afshar N, Haghdoost AA. Exploring maternal mortality in relation to socioeconomic factors in Iran. Singapore Med J. 2012;53(10):684-9.

41. Rajaratnam JK, Marcus JR, Flaxman AD, Wang H, Levin-Rector A, Dwyer L, et al. Neonatal, postneonatal, childhood, and under-5 mortality for 187 countries, 1970-2010: a systematic analysis of progress towards Millennium Development Goal 4. Lancet. 2010;375(9730):1988-2008. doi: 10.1016/S01406736(10)60703-9.

42. Khosravi, A., M. Motlagh, and S. Emami Razavi, The Iranian vital horoscope; appropriate tool to collect health statistics in rural areas. Iranian J Publ Health. 2009;38(1): 74-80.

43. Javanparast S, Baum F, Labonte R, Sanders D, Heidari G, Rezaie S. A policy review of the community health worker programme in Iran. J Public Health Policy. 2011;32(2):263-76. doi: 10.1057/jphp.2011.7.

44. Nasseri K, Sadrizadeh B, Malek-Afzali H, Mohammad K, Chamsa M, Cheraghchi-Bashi MT, et al. Primary health care and immunisation in Iran. Public Health. 1991;105(3):229-38. doi: 10.1016/s0033-3506(05)80112-x

45. Zahraei SM, Marandi A, Sadrizadeh B, Gouya MM, Rezaei P, Vazirian P, et al. Role of National Immunization Technical Advisory Group on improvement of immunization programmes in the Islamic Republic of Iran. Vaccine. 2010;28(Suppl 1):A35-8. doi: 10.1016/j.vaccine.2010.02.030.

46. Gouya MM. Expanded programme on immunization in Iran: last 3 decades achievements from 1979 to 2008. Iran J Public Health. 2009;38(Suppl 1): 8.

47. Sadrizadeh B. Evidence for policy in Iran. Iran J Public Health. 2009;38(Suppl 1):17-8.

48. Javanparast S, Baum F, Labonte R, Sanders D, Rajabi Z, Heidari G. The experience of community health workers training in Iran: a qualitative study. BMC Health Serv Res. 2012;12:291. doi: 10.1186/1472-6963-12-291.

49. Doshmangir L, Rashidian A, Jafari M, Takian A, Ravaghi H. Opening the black box: the experiences and lessons from the public hospitals autonomy policy in Iran. Arch Iran Med. 2015;18(7):416-24.

50. Aghajanian A, Merhyar AH. Fertility, contraceptive use and family planning program activity in the Islamic Republic of Iran. Int Fam Plan Perspect. 1999:25(2): 98-102.

51. Kalhor R, Azmal M, Kiaei MZ, Eslamian M, Tabatabaee SS, 
Jafari M. Situational analysis of human resources in family physician program: survey from iran. Mater Sociomed. 2014;26(3):195-7. doi: 10.5455/msm.2014.26.195-197.

52. Nasiripour A, Motaghi M, Navvabi N. The performance of referral system from the perspective of family physicians of Kashan University of Medical Sciences: 2007-20012. Journal of Health Promotion Management. 2014;3(3):58-68.

53. Takian A, Rashidian A, Doshmangir L. The experience of purchaser-provider split in the implementation of family physician and rural health insurance in Iran: an institutional approach. Health Policy Plan. 2015;30(10):1261-71. doi: 10.1093/heapol/czu135.

54. Rashidian A, Salavati S, Hajimahmoodi H, Kheirandish M. Does rural health system reform aimed at improving access to primary health care affect hospitalization rates? An interrupted time series analysis of national policy reforms in Iran. J Health Serv Res Policy. 2019;24(2):73-80. doi: 10.1177/1355819618815721.

55. Alizadeh M, Jabbari Birami H, Moradi S. Reproductive Health of Women in Rural Areas of East Azerbaijan - Iran, before and after Implementation of rural Family Physician Program: an Ecologic Study. J Caring Sci. 2015;4(4):321-30. doi: 10.15171/ jcs.2015.032.

56. Ministry of Health and Medical Education. Operational Guide for Family Physician Project Implementation [Persian]. Tehran: Ministry of Health and Medical Education; 2012.

57. Bazyar M, Rashidian A, Kane S, Vaez Mahdavi MR, Akbari Sari A, Doshmangir L. Policy Options to Reduce Fragmentation in the Pooling of Health Insurance Funds in Iran. Int J Health Policy Manag. 2016;5(4):253-8. doi: 10.15171/ijhpm.2016.12.

58. Bazyar M, Rashidian A, Sakha MA, Doshmangir L, Rahimi $\mathrm{N}$, Ranjbar M, et al. Stakeholders analysis of merging social health insurance funds in Iran: what kind of interests they may gain or lose? Int J Health Plann Manage. 2019;34(1):157-176. doi: 10.1002/hpm.2605.

59. Doshmangir L, Bazyar M, Doshmangir P, Mostafavi $H$, Takian A. Infrastructures required for the expansion of family physician program to urban settings in Iran. Arch Iran Med. 2017;20(9):589-597.

60. Piroozi B, Rashidian A, Moradi G, Takian A, Ghasri H, Ghadimi T. Out-of-Pocket and Informal Payment Before and After the Health Transformation Plan in Iran: Evidence from Hospitals Located in Kurdistan, Iran. Int J Health Policy Manag. 2017;6(10):573-586. doi: 10.15171/ijhpm.2017.16.

61. Doshmangir L, Bazyar M, Najafi B, Haghparast-Bidgoli $\mathrm{H}$. Health financing consequences of implementing health transformation plan in Iran: achievements and challenges. Int J Health Policy Manag. 2019;8(6):384-6. doi: 10.15171/ ijhpm.2019.18.

62. Asadi-Lari M, Sayyari AA, Akbari ME, Gray D. Public health improvement in Iran--lessons from the last 20 years. Public Health. 2004;118(6):395-402. doi: 10.1016/j. puhe.2004.05.011

63. King M. An Iranian Experiment in Primary Health Care. The
West Azerbaijan Project. London: Oxford University Press; 1983.

64. Marandi SA, Azizi F, Jamshidi HR, Larijani MB. Health in Islamic Republic of Iran. Geneva: World Health Organization (UNICEF); 1998.

65. Takian A, Rashidian A, Kabir MJ. Expediency and coincidence in re-engineering a health system: an interpretive approach to formation of family medicine in Iran. Health Policy Plan. 2011;26(2):163-73. doi: 10.1093/heapol/czq036.

66. Alexander JC, Colomy PB. Differentiation theory and social change: comparative and historical perspectives: Columbia University Press; 1990.

67. Aguilera RV, Rupp DE, Williams CA, Ganapathi J. Putting the $S$ back in corporate social responsibility: a multilevel theory of social change in organizations. Academy of Management Review. 2007;32(3):836-63.

68. Easton, D. The Political System: An Inquiry into the State of Political Science. New York: Knopf.1953.

69. John P. Analysing Public Policy. London: Pinter, 1998:227.

70. Bahador, M. A route to well-being: the report of the delegation to assess health and medical care problems in Iran [Persian]. Tehran, Iran: Rahnema Press; 1977

71. Doshmangir L, Bazyar M, Majdzadeh R, Takian A. So Near, So Far: Four Decades of Health Policy Reforms in Iran, Achievements and Challenges. Arch Iran Med. 2019;22(10):592-605.

72. Buse K. Addressing the theoretical, practical and ethical challenges inherent in prospective health policy analysis. Health Policy Plan. 2008;23(5): 351-60.

73. Sabatier PA. Theories of the Policy Process: Theoretical Lenses on Public Policy. Boulder. Colorado, United States: Westview Press; 2007.

74. Sabatier $\mathrm{P}$, Jenkins-Smith H. Policy change and learning: an advocacy coalition approach. Boulder, Colorado, United States: Westview Press; 1993.

75. Cheung KK, Mirzaei M, Leeder S. Health policy analysis: a tool to evaluate in policy documents the alignment between policy statements and intended outcomes. Aust Health Rev. 2010;34(4):405-13.

76. Buse K, Mays N, Walt G. Making Health Policy. UK: McGrawHill Education; 2012.

77. Adam T, de Savigny D. Systems thinking for strengthening health systems in LMICs: need for a paradigm shift. Health Policy Plan. 2012;27(Suppl 4):iv1-3. doi: 10.1093/heapol/ Czs084

78. Arah OA, Klazinga NS, Delnoij DM, ten Asbroek AH, Custers T. Conceptual frameworks for health systems performance: a quest for effectiveness, quality, and improvement. Int J Qual Health Care. 2003;15(5):377-98. doi: 10.1093/intqhe/mzg049

79. Turnock BJ, Handler AS. From measuring to improving public health practice. Annu Rev Public Health. 1997;18:261-82. doi: 10.1146/annurev.publhealth.18.1.261

80. Lebaron SW, Schultz SH. Family medicine in Iran: the birth of a new specialty. Fam Med. 2005;37(7):502-5. 